\title{
Enhanced metathesis of ethylene and 2-butene on tungsten incorporated ordered mesoporous silicates
}

\author{
Jian-Feng Wu, ${ }^{\mathrm{a}}$ Anand Ramanathan, ${ }^{\mathrm{a}}$ William K. Snavely, ${ }^{\mathrm{a}}$ Hongda Zhu, ${ }^{\mathrm{a}, \mathrm{b}}$ Andrzej Rokicki, \\ and Bala Subramaniam ${ }^{\mathrm{a}, \mathrm{b}} *$ \\ ${ }^{a}$ Center for Environmentally Beneficial Catalysis, The University of Kansas, Lawrence, KS 66047, USA. \\ ${ }^{b}$ Department of Chemical and Petroleum Engineering, The University of Kansas, Lawrence, KS 66045, USA. \\ *Corresponding author. Tel.: +1-785-864-2903. Fax: +1-785-864-6051. E-mail: bsubramaniam@ku.edu
}

\begin{abstract}
Tungsten-incorporated 3D mesoporous silicates, W-KIT-6, W-KIT-5, and W-SBA-16 catalysts, outperform supported tungsten oxide catalysts $\left(\mathrm{WO}_{3} / \mathrm{SiO}_{2}\right.$ and $\left.\mathrm{WO}_{3} / \mathrm{KIT}-6\right)$ for the metathesis of ethylene and 2-butene to propene at $450^{\circ} \mathrm{C}$. All catalysts exhibit steady activity and stability during $7 \mathrm{~h}$ runs in a fixed-bed reactor. Furthermore, on all mesoporous catalysts, a maximum propylene yield was obtained at an optimum $\mathrm{W}$ loading at which the catalyst acidity is also maximum. Slightly delayed addition of the W source during the one-pot synthesis protocol markedly improves the propene yield on W-KIT-6 catalyst. XPS results conclusively show that this enhancement is due to preferential enrichment of active $\mathrm{W}$ species on the catalyst surface. Extended runs lasting five days reveal very little loss of activity even which is easily recovered by calcination in air.
\end{abstract}

\section{Keywords}

Metathesis, ethylene, 2-butene, tungsten, ordered mesoporous silicates

\section{Introduction}

In the United States, the supply of natural gas liquids (NGLs) has increased dramatically as a collateral product of shale gas extraction. While this is expected to provide an oversupply of ethylene, but a shortage of propene is expected as a result of decreased naphtha availability [1,2]. Hence, the synthesis of propene from ethylene via olefin metathesis [3-9] is receiving renewed interest. Current industrial process for the metathesis of ethylene and 1-butene to propene [the so-called olefin conversion technology or OCT] employs $\mathrm{WO}_{3} / \mathrm{SiO}_{2}$ catalyst, producing a propene yield of $\sim 54 \%$ at approximately $30-35$ bar and $>260^{\circ} \mathrm{C}$ [5]. To develop catalysts that operate at lower pressures and temperatures, a number of experimental [10-30] and theoretical $[31,32]$ investigations have been reported. A majority of the investigated catalysts involve Re, Mo, and $\mathrm{W}$ oxides. 
Mesoporous silicas possessing high surface area, large pore volume, high thermal stability and low diffusion resistance offer an attractive alternative to amorphous non-ordered silica supports $[33,34]$. For olefin metathesis, several W-, Mo-, and Re-incorporated mesoporous silicas with different pore structures have been explored. These include $\mathrm{WO}_{3} / \mathrm{MTS}-9$ [26] and $\mathrm{MoO}_{3} / \mathrm{HMS}$ [13] catalysts synthesized by the impregnation method, and W-SBA-15 [11], W-MCM-41 [11], W-KIT-6 [27, 35], W-FDU-12 [28], Mo-SBA-15 [36], Mo-KIT-5 [25] catalysts synthesized by a one-pot method, $\mathrm{SiO}_{2}-\mathrm{Al}_{2} \mathrm{O}_{3}-\mathrm{MoO}_{3}$ [37, 38], Re-Si-Al mixed oxides [29, 39], WSi and WSiAl catalysts [40] synthesized by non-hydrolytic sol-gel method. Although mesoporous silica supports with different pore structures have been reported for olefin metathesis, the influence of structural differences on catalytic performance is unclear. In this work, we compared the performance of three types of $\mathrm{W}$-incorporated ordered mesoporous silicates with different 3D structures for the metathesis of 2-butene and ethylene to propene. These include W-KIT-6 (Ia3d) [41], W-KIT-5 (Fm3m) [42], and W-SBA-16 (Im3m). While W-KIT-6 catalyst had been investigated previously for olefin metathesis (1-butene + ethylene) $[12,30]$, there are no reports of W-KIT-6, W-KIT-5 and W-SBA-16 catalysts for this reaction (2-butene + ethylene).

The activity of supported metathesis catalysts depends on the catalyst synthesis procedure. Catalysts prepared using the simple impregnation method typically suffer from low dispersion of the active $\mathrm{W}$ precursors and the generation of inactive bulk $\mathrm{WO}_{3}$ species [10, 26, 43]. A higher dispersion of $\mathrm{W}$ species in the silica framework is achievable by one-pot methods [11, 41, 44]. However, tungsten accessibility could be a problem if the tungsten species are buried sufficiently deep in the framework. To overcome this problem, we investigate herein a modified one-pot synthesis method in which the addition of the tungsten source is delayed until after partial hydrolysis of the silica source, increasing the probability of more active tungsten precursors being deposited on the surface. Appropriate analytical techniques (XRD, UV/Vis and XPS) are employed to gain fresh insights into the relative distributions of $\mathrm{W}$ species on the catalysts prepared by various synthesis procedures and to correlate the relative metathesis activity of such catalysts.

\section{Experimental}

\subsection{Chemicals}

Triblock copolymer Pluronic P123 $\left(\mathrm{EO}_{20}-\mathrm{PO}_{70}-\mathrm{EO}_{20}\right.$, average $\left.\mathrm{MW}=5800\right)$, Pluronic F127, tetraethyl orthosilicate (TEOS, 98\%), fumed silica (particle size: $0.007 \mu \mathrm{m}$, surface area: $390 \pm$

$40 \mathrm{~m}^{2} / \mathrm{g}$, batch \#: $\left.119 \mathrm{k} 0031\right)$, and ammonium metatungstate hydrate $\left[\left(\mathrm{NH}_{4}\right)_{6} \mathrm{H}_{2} \mathrm{~W}_{12} \mathrm{O}_{40} \cdot \mathrm{xH}_{2} \mathrm{O}, \geq\right.$ $85 \% \mathrm{WO}_{3}$ basis], and tungsten oxide were purchased form Sigma-Aldrich. Sodium tungstate (99.0-101.0\%, $\mathrm{Na}_{2} \mathrm{WO}_{4} \cdot 2 \mathrm{H}_{2} \mathrm{O}$ ) was purchased from Alfa Aesar. 1-Butanol (HPLC grade) and hydrochloric acid (certified ACS plus) were purchased from Fisher Scientific. 2-Butene ( $\geq 95$ wt $\%$, 39\% cis-2-butene and 61\% trans-2-butene) and ethylene ( $\geq 99.5 \%)$ were purchased from Matheson Tri-Gas Inc. All the reagents were used as received without further purification. 


\subsection{Catalyst preparation}

\subsubsection{KIT-6 support}

KIT-6 support (i.e., without addition of W source solution) was synthesized according to procedure described elsewhere [45].

\subsection{2. $\mathrm{WO}_{3} / \mathrm{SiO}_{2}$ and $\mathrm{WO}_{3} / \mathrm{KIT}-6$ catalysts}

$\mathrm{WO}_{3} / \mathrm{SiO}_{2}$ and $\mathrm{WO}_{3} / \mathrm{KIT}-6$ catalysts were prepared by wet impregnation of the silica supports (fumed $\mathrm{SiO}_{2}$ and KIT-6, respectively) with an aqueous solution of ammonium metatungstate, followed by sonication for $0.5 \mathrm{~h}$ and stirring for $24 \mathrm{~h}$ at room temperature $[27,46]$. The impregnated samples were first dried in a rotary evaporator at $70^{\circ} \mathrm{C}$ for $0.5 \mathrm{~h}$, then dried at $100^{\circ} \mathrm{C}$ overnight in an oven. The resulting samples were treated in flowing air from room temperature to $550^{\circ} \mathrm{C}$ at a ramp rate of $1^{\circ} \mathrm{C} / \mathrm{min}$, followed by calcination at $550^{\circ} \mathrm{C}$ for $5 \mathrm{~h}$ and natural cooling down to room temperature. The resulting solids are denoted as $\mathrm{WO}_{3} / \mathrm{SiO}_{2}$ (x) and $\mathrm{WO}_{3} / \mathrm{KIT}-6$ ( $\mathrm{x}$ ) where $\mathrm{x}$ represents the weight percent of tungsten in these catalysts, respectively.

\subsubsection{Synthesis of W-KIT-6, W-KIT-5 and W-SBA-16 catalysts}

W-KIT-6 [41], W-KIT-5 [42] and W-SBA-16 [47] catalysts were synthesized as described in the cited publications and the resulting catalyst samples are denoted as W-KIT-6 (x), W-KIT-5 (x) and W-SBA-16 (x) where $\mathrm{x}$ represents the weight percent of tungsten in the samples.

For preparing W-KIT-6 catalysts, a typical synthesis is as follows. $4.5 \mathrm{~g}$ P123 were dissolved in $160 \mathrm{~mL} \mathrm{H}_{2} \mathrm{O}$ and $8.3 \mathrm{~g} 37.1 \mathrm{wt} \% \mathrm{HCl}$ at $38 \pm 2{ }^{\circ} \mathrm{C}$. Then, $4.5 \mathrm{~g}$ 1-butanol were added and the system was stirred for $1 \mathrm{~h}$. Following this step, $9.7 \mathrm{~g}$ TEOS and the desired amount of sodium tungstate were added and the stirring continued for $24 \mathrm{~h}$. The resulting mixture was transferred into a Teflon-lined autoclave and heated to $100^{\circ} \mathrm{C}$ for $24 \mathrm{~h}$. The solid product was collected and washed by deionized water, then dried at $100^{\circ} \mathrm{C}$ overnight. The obtained sample was calcined in flowing air at $550^{\circ} \mathrm{C}$ for $10 \mathrm{~h}$ at a ramp rate of $1^{\circ} \mathrm{C} / \mathrm{min}$.

For preparing W-KIT-5 catalysts, the synthesis procedure is as follows. $2.7 \mathrm{~g}$ F127 were dissolved in $130 \mathrm{~mL} \mathrm{H}_{2} \mathrm{O}$ and $5.3 \mathrm{~g} 37.1 \mathrm{wt} \% \mathrm{HCl}$ at $45 \pm 2{ }^{\circ} \mathrm{C}$. Then, $13.0 \mathrm{~g}$ TEOS and the desired amount of sodium tungstate were added and the stirring was continued for $20 \mathrm{~h}$. The crystallization, the product collection and calcination procedures are similar to those for W-KIT6.

For preparing W-SBA-16 catalysts, the synthesis procedure is as follows. $2.85 \mathrm{~g}$ F127 were dissolved in $135 \mathrm{~mL} \mathrm{H}_{2} \mathrm{O}$ and $5.6 \mathrm{~g} 37.1 \mathrm{wt} \% \mathrm{HCl}$ at $45 \pm 2{ }^{\circ} \mathrm{C}$. Then, $8.65 \mathrm{~g}$ 1-butanol were added to the above mixture and the stirring was continued for $1 \mathrm{~h}$. Following this step, $13.8 \mathrm{~g}$ TEOS and the desired amount of sodium tungstate were added and the stirring was continued for $20 \mathrm{~h}$. The crystallization, the product collection and calcination procedures are similar to those for W-KIT-6.

\subsubsection{Modified W-KIT-6 synthesis}


The following modified W-KIT-6 synthesis method was adopted to increase the population of accessible $\mathrm{W}$ species on the catalyst surface. The modification involved delaying the addition of the tungsten source. Following the dissolution of $\mathrm{P} 123$ triblock copolymer in conc. $\mathrm{HCl}$ solution ( $\sim 0.5 \mathrm{~mol} / \mathrm{L})$ and the addition of TEOS, the desired amount of sodium tungstate (dissolved in 5 $\mathrm{mL} \mathrm{H}_{2} \mathrm{O}$ ) was added following a delay of 1, 2, 3, 5 and $8 \mathrm{~h}$. After the addition of the tungsten source, the mixture was stirred for $24 \mathrm{~h}$. The resulting mixture was transferred into a Teflonlined autoclave and heated at $100^{\circ} \mathrm{C}$ for $24 \mathrm{~h}$. The solid product was collected and washed with deionized water, then dried overnight at $100^{\circ} \mathrm{C}$ and calcined at $550^{\circ} \mathrm{C}$ for $5 \mathrm{~h}$. The catalyst samples are denoted as W-KIT-6 $(\mathrm{t}, \mathrm{x})$ where $\mathrm{t}$ and $\mathrm{x}$ represent the delayed addition time of the tungsten source (in hours) and the tungsten weight percent, respectively.

\subsection{Catalyst characterization}

The wide-angle XRD patterns were collected on a Bruker X-ray diffractometer using Mo $K \alpha$ radiation $(\lambda=0.71073 \AA)$ operated at $50 \mathrm{kV}$ and $35 \mathrm{~mA}$. The small-angle XRD patterns were collected on a Rigaku system with an S-MAX 3000 instrument operated at $45 \mathrm{kV}$ and $0.66 \mathrm{~mA}$. The tungsten and silicon contents of the catalysts were determined by inductively coupled plasma optical emission spectrometry (ICP-OES) using a Horiba Jobin Yvon JY 2000 instrument. The textural properties (BET surface area, pore volume and pore size distribution) of the catalysts were measured on a Quantachrome NOVA 2000e instrument as described elsewhere $[41,42,47]$. The total acidity of the catalysts was measured by temperature-programmed desorption of ammonia ( $\mathrm{NH}_{3}$-TPD) on a Micromeritics Autochem 2910 instrument equipped with a thermal conductivity detector (TCD) as described elsewhere [41]. The structure of the surface species was analyzed by diffuse reflectance UV/Vis (DR UV-Vis) spectra with a PerkinElmer Lambda 850 spectrometer equipped with diffuse reflectance integrating sphere, using Spectralon as the reference.

X-ray photoelectron spectroscopy (XPS) was studied using PHI 5000 Versa Probe II instrument. Monochromated Al $K \alpha(50 \mathrm{~W}, 15 \mathrm{kV})$ X-ray was used for XPS measurements and the X-ray beam diameter was $200 \mu \mathrm{m}$. A dual-beam charge neutralizer was used to compensate the charging effect. The spherical capacitance analyzer was operated with a pass energy of $46.95 \mathrm{eV}$. All XPS peaks were referenced to the $\mathrm{Si}_{2 \mathrm{p}}$ peak at $103.3 \mathrm{eV}$. To get the information from the outermost layer, the sample stage was tilted to $20^{\circ}$. Before the analysis, the surface of the sample was sputtered by $\mathrm{Ar}^{+}$ion (2.0 $\left.\mathrm{keV}\right)$ for $5 \mathrm{~min}$ [48].

\subsection{Evaluation of metathesis activity}

The catalytic activity of various $\mathrm{W}$-incorporated catalysts for metathesis of ethylene and 2butene to propene was evaluated in a continuous flow, stainless steel fixed-bed reactor with i.d. $=$ $9.4 \mathrm{~mm}$. $1.0 \mathrm{~g}$ of catalyst $\left(0.425-0.850 \mathrm{~mm}\right.$ diameter, precalcined in a muffle furnace at $550^{\circ} \mathrm{C}$ for $5 \mathrm{~h}$ ) was loaded in the central portion of the reactor, held in place by a stainless steel collar and glass wool. A thermocouple probe was placed in the catalyst bed to measure the catalyst temperature. After pretreatment at $550^{\circ} \mathrm{C}$ for $1 \mathrm{~h}$ under $\mathrm{N}_{2}(50 \mathrm{std} \mathrm{cm} / \mathrm{min})$ to remove moisture, the reactor was cooled down to the reaction temperature. After the $\mathrm{N}_{2}$ flow was stopped, ethylene and 2-butene were introduced into the reactor via mass flow controllers at predetermined flow 
rates with the ethylene/2-butene molar ratio of 3 . The metathesis reactions were conducted at $450^{\circ} \mathrm{C}$ or $500^{\circ} \mathrm{C}$ and $1 \mathrm{~atm}$, with a weight hourly space velocity (WHSV) of $2.0 \mathrm{~h}^{-1}$ based on the total ethylene +2 -butene flow rate. The reaction products were analyzed by an on-line Varian CP-3800 gas chromatograph equipped with an Agilent GS-gaspro ${ }^{\circledR}$ column $(30 \mathrm{~m} \times 0.320 \mathrm{~mm})$ and a flame ionization detector (FID). The line between the reactor and the six-way valve was heated to $160^{\circ} \mathrm{C}$ to prevent products condensation. A typical gas chromatograph based on sampling and analysis of the reactor effluent stream is shown in Fig. S1.

The following equations are used in assessing the performance of the W-based catalysts and mass balance closure:

$$
\begin{gathered}
X_{2-\text { butene }}=\frac{[2-\text { butene }]_{\text {in }}-[2-\text { butene }]_{\text {out }}}{[2-\text { butene }]_{\text {in }}} \times 100 \% \\
S_{\text {propene }}=\frac{[\text { propene }]_{\text {out }}}{[2-\text { butene }]_{\text {in }}-[2-\text { butene }]_{\text {out }}} \times 100 \% \\
Y_{\text {propene }}=X_{2-\text { butene }} \times S_{\text {propene }} \times 100 \% \\
\text { Mass balance closure }=\frac{[\text { Total carbon in products }]}{[\text { Total carbon in feed components }]} \times 100 \%
\end{gathered}
$$

where $X_{2 \text {-butene }}$ denotes 2-butene (the limiting reactant) conversion, $S_{\text {propene }}$ denotes propene selectivity, $Y_{\text {propene }}$ denotes propene yield, and $[\mathrm{A}]_{\text {in }}$ or $[\mathrm{A}]_{\text {out }}$ denotes the molar flow rate of $\mathrm{A}$ in the reactants or products $(\mathrm{A}=2$-butene or propene $)$. The mass balance closure at steady state was $100 \pm 2.5 \%$ which is within experimental error. The conversions were shown to be free from internal and external transport limitations by varying the catalyst particle size, catalyst amount and flow rate while maintaining identical WHSV in all the runs and by confirming that the variations in conversion were within experimental error. Details are given in the supplementary information (Fig. S2).

Given that the actual number of active $\mathrm{W}$ species is difficult to characterize under working conditions, an apparent turnover frequency (TOF) is defined as the moles of propene formed per mole of W per second [19].

$$
\operatorname{TOF}\left(s^{-1}\right)=\frac{W H S V_{2-\text { butene }}\left(g \cdot h^{-1}\right) / M_{2-\text { butene }}\left(g \cdot \mathrm{mol}^{-1}\right) \times \operatorname{Yield}_{\text {propene }}}{3600\left(s \cdot h^{-1}\right)} / \frac{m_{\text {catalyst }}(g) \times W w t \%}{M_{W}\left(g \cdot m_{0}^{-1}\right)}
$$

Where $\mathrm{WHSV}_{2 \text {-butene }}$ is the weight hourly space velocity of 2-butene, $\mathrm{M}_{2 \text {-butene }}$ is the molar mass of 2-butene, $\mathrm{m}_{\text {catalyst }}$ is the weight of catalyst, $\mathrm{W} w \mathrm{wt}$ is the tungsten loading in $\mathrm{wt} \%$, and $\mathrm{M}_{\mathrm{W}}$ is the $\mathrm{W}$ molar mass. The apparent TOF assumes that all available $\mathrm{W}$ species exhibit the same activity. Thus, variations in apparent TOF for nearly identical $\mathrm{W}$ loading should provide comparative information on the number of accessible active $\mathrm{W}$ species. Following a run, the reactor was cooled, and the used catalyst was recovered and transferred into a glass vial for further characterization. 


\section{Results and discussion}

\subsection{Textural and structural properties}

The composition and textural properties (surface area, pore volume, and pore size) of W-KIT-6, W-KIT-5 and W-SBA-16 materials yield values in the range reported previously [41, 42, 47] (Table S1). Within the same family of materials, the pore volume and surface area decrease along with an increase in $\mathrm{W}$ loading, also as reported previously. The wide-angle XRD patterns of catalysts [ $\mathrm{WO}_{3} / \mathrm{SiO}_{2}, \mathrm{WO}_{3} / \mathrm{KIT}-6, \mathrm{~W}-\mathrm{KIT}-6, \mathrm{~W}-\mathrm{KIT}-5, \mathrm{~W}-\mathrm{SBA}-16$, W-KIT-6 (2 h), W-KIT-6 (t) where $\mathrm{t}=1,3,5,8 \mathrm{~h}$ ), and crystalline $\mathrm{WO}_{3}$ ] showed the characteristic patterns expected of these materials. These patterns are shown in Fig. 1 and Figs. S3-S8 in the supporting information. Compared with the $\mathrm{WO}_{3}$-impregnated catalysts $\left[\mathrm{WO}_{3} / \mathrm{SiO}_{2}\right.$ (7.4) and $\mathrm{WO}_{3} / \mathrm{KIT}-6$ (7.6)], the Wincorporated mesoporous silicates [W-KIT-6, W-KIT-5, W-SBA-16, and W-KIT-6 (2 h)] synthesized using the one-pot method with or without delayed addition of the $\mathrm{W}$ source show either no or low-intensity crystalline $\mathrm{WO}_{3}$ peaks at similar $\mathrm{W}$ loading. This suggests superior tungsten dispersion in the one-pot silicates. Comparison of wide-angle XRD patterns for W-KIT6 (8.7) and W-KIT-6 (2 h, 9.2) catalysts is provided in Fig. S7 in the supporting information. Clearly, the peak intensity of crystalline $\mathrm{WO}_{3}$ on W-KIT-6 $(2 \mathrm{~h}, 9.2)$ catalyst is lower than the corresponding peak in the W-KIT-6 (8.7) catalyst, indicating that less bulk $\mathrm{WO}_{3}$ was formed on the W-KIT-6 $(2 \mathrm{~h}, 9.2)$ catalyst. For W-KIT-6 $(\mathrm{t})$ catalysts $(\mathrm{t}=1,3,5,8 \mathrm{~h})$ prepared with delayed addition of the $\mathrm{W}$ source, the peak intensity corresponding to crystalline $\mathrm{WO}_{3}$ increases with the delay time from 1 to $5 \mathrm{~h}$, then remains constant from 5 to $8 \mathrm{~h}$ (Fig. 1).

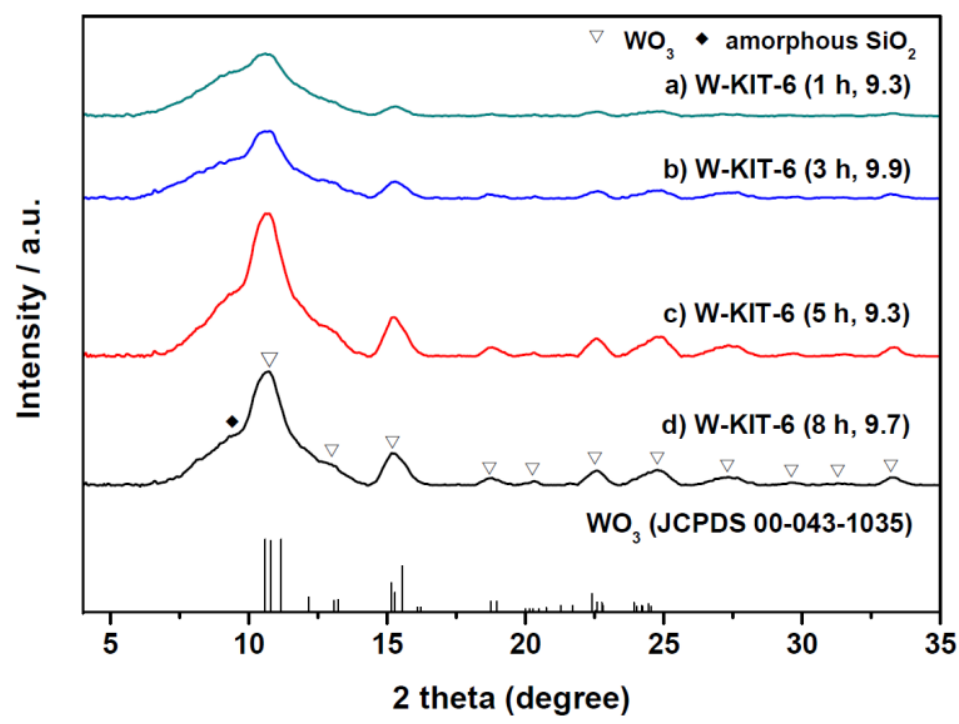

Fig. 1. Wide-angle XRD patterns of (a) W-KIT-6 (1 h, 9.3), (b) W-KIT-6 (3 h, 9.2), (c) W-KIT-6 $(5 \mathrm{~h}, 9.3)$, and (d) W-KIT-6 (8 h, 9.7) catalysts. The unfilled triangles indicate the $\mathrm{WO}_{3}$ peaks, while the broad hump between $7-14^{\circ}$ (indicated by the black diamond) suggests the presence of amorphous $\mathrm{SiO}_{2}$. 
Small-angle XRD patterns reveal that the long-range structural ordering of KIT-6 was maintained following wet impregnation of $\mathrm{WO}_{3}$ (see Fig. S9). The W-KIT-6, W-KIT-5 and WSBA-16 materials also show clear long-range structural ordering (Fig. S10), as demonstrated previously $[41,42,47]$ for these materials. At higher tungsten loadings $(>7.2 \mathrm{wt} \%)$, the intensities of the (211) diffraction bands of W-KIT-6 catalysts become weaker, indicating a decrease in the structural order (Fig. S11). For a similar W loading, the delayed addition of the W source also influences the structural order of W-KIT-6 $(\mathrm{t})$ catalysts $(\mathrm{t}=1,3,5,8 \mathrm{~h})$ with the longer delays ( 5 and $8 \mathrm{~h}$ ) yielding a better structural order (Fig. S12).

\subsection{Characterization of surface species on $\mathrm{W}-\mathrm{KIT}-6, \mathrm{WO}_{3} / \mathrm{KIT}-6$, and $\mathrm{WO}_{3} / \mathrm{SiO}_{2}$ catalysts by UV/Vis diffuse reflectance spectroscopy}

The UV/Vis spectra of fresh W-catalysts (W-KIT-6, $\mathrm{WO}_{3} / \mathrm{KIT}-6$, and $\mathrm{WO}_{3} / \mathrm{SiO}_{2}$ ) were recorded in 200-800 $\mathrm{nm}$ region. As shown in Fig. 2, two absorption bands at 225 and $262 \mathrm{~nm}$ were observed for all W-catalysts. An additional absorption band at $400 \mathrm{~nm}$ was recorded for samples with $\mathrm{W}$ loading higher than $5.9 \mathrm{wt} \%$ in all $\mathrm{W}$-catalysts. These bands were not observed in the case of pure KIT-6 (Fig. S13a), indicating that the absorption bands result from the incorporation of tungsten species. The band at $225 \mathrm{~nm}$ is due to the ligand-to-metal charge transfer, which stems from the isolated $\left[\mathrm{WO}_{4}\right]^{2-}$ species with tetrahedral configuration $[11,18,49]$. This assignment was confirmed by the UV/Vis DRS spectroscopy of $\mathrm{Na}_{2} \mathrm{WO}_{4}$ (Fig. S13b). The band at $262 \mathrm{~nm}$ is attributed to $\mathrm{O}^{2-} \rightarrow \mathrm{W}^{6+}$ charge transfer, which corresponds to octahedral polytungstate species $[11,18,49]$. The absorption band at approximately $400 \mathrm{~nm}$ is due to bulk $\mathrm{WO}_{3}$ species $[11,18,49]$, which was also confirmed by comparison with the pure $\mathrm{WO}_{3}($ Fig. S13c). Clearly, the one-pot W-KIT-6 (5.9) catalyst with lower W loading shows higher band intensities at 225 and $262 \mathrm{~nm}$ compared to the impregnated $\mathrm{WO}_{3} / \mathrm{KIT}-6$ (7.6) and $\mathrm{WO}_{3} / \mathrm{SiO}_{2}(7.4)$ catalysts. This indicates that the one-pot W-KIT-6 (5.9) catalyst has higher concentrations of tetrahedral and octahedral $\mathrm{W}$ species than impregnated $\mathrm{WO}_{3} / \mathrm{KIT}-6$ (7.6) and $\mathrm{WO}_{3} / \mathrm{SiO}_{2}(7.4)$ catalysts. Comparative UV/Vis spectra for W-KIT-6 (8.7) and W-KIT-6 (2 h, 9.2) catalysts is provided in Fig. S17 in the supporting information. The W-KIT-6 (2 h, 9.2) catalyst displays higher band intensity at $262 \mathrm{~nm}$ (octahedral polytungstate species) but lower band intensity at $400 \mathrm{~nm}$ (bulk $\mathrm{WO}_{3}$ species) compared to the W-KIT-6 (8.7) catalyst. This again suggests a higher population of active $\mathrm{W}$ species and a lower population of inactive bulk $\mathrm{WO}_{3}$ species on the W-KIT-6 (2 h, 9.2) catalyst surface. 


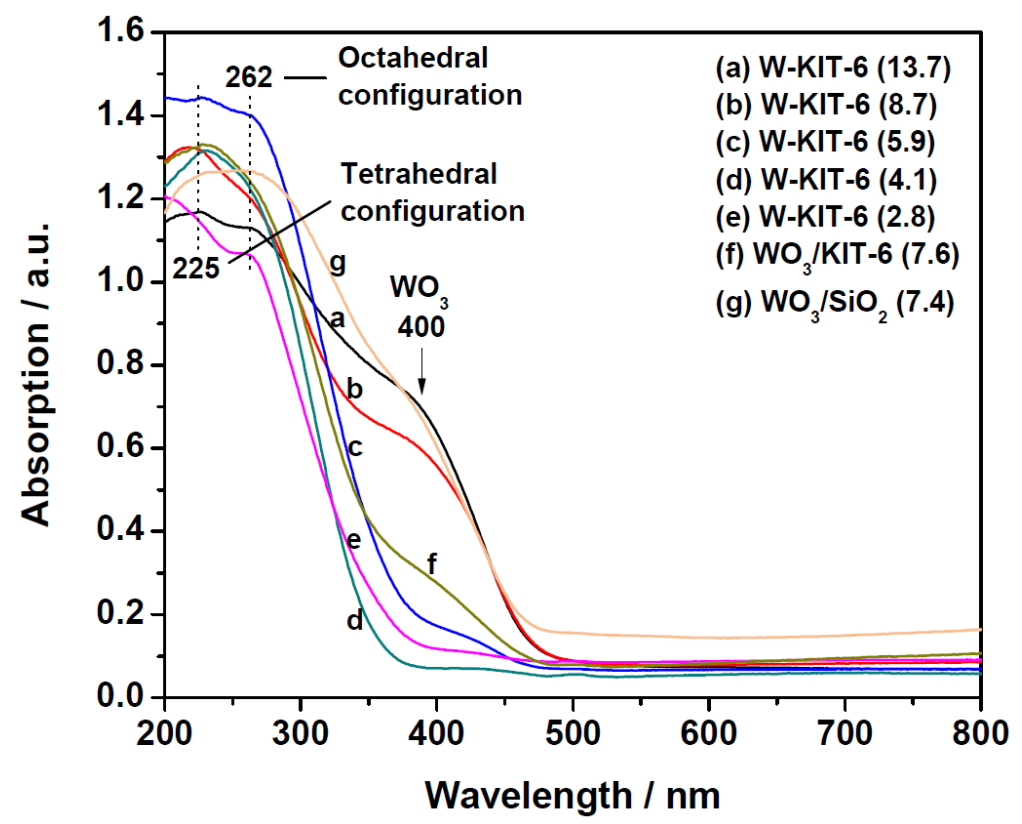

Fig. 2. UV/Vis DRS patterns of fresh W-catalysts: (a) W-KIT-6 (13.7), (b) W-KIT-6 (8.7), (c) W-KIT-6 (5.9), (d) W-KIT-6 (4.1), (e) W-KIT-6 (2.8), (f) $\mathrm{WO}_{3} / \mathrm{KIT}-6$ (7.6), and (g) $\mathrm{WO}_{3} / \mathrm{SiO}_{2}$ (7.4) catalysts.

\subsection{Benchmarking experiments with $\mathrm{WO}_{3}$-impregnated silicas as catalysts}

Industrial ethylene +1 -butene metathesis catalysts are typically based on silica-supported $\mathrm{WO}_{3}$ with proprietary additives to enhance catalyst stability [5]. Benchmarking experiments with $\mathrm{WO}_{3}$-impregnated silica supports, $\mathrm{WO}_{3} / \mathrm{SiO}_{2}$ (7.4) and $\mathrm{WO}_{3} / \mathrm{KIT}-6$ (7.6), were first performed. As can be seen in Fig. 3, there is an approximately $1.5 \mathrm{~h}$ break-in period as reported in previous studies [43, 50, 51]. Thomas et al. [43] observed such a period on $\mathrm{WO}_{3} / \mathrm{SiO}_{2}$ catalyst, which is attributed to the gradual formation of the active $\mathrm{W}$-carbene species on the catalyst. Luckner and Wills [52] speculated that the break-in period results from the strong adsorption of an organic intermediate or fragment from propene disproportionation (the reverse reaction of the metathesis of ethylene and 2-butene to propene). The propene yield is stable following the break-in period for the $7 \mathrm{~h}$ duration of the experiment. A moderately higher activity (33.2 $\pm 0.3 \%$ propene yield) was observed on $\mathrm{WO}_{3} / \mathrm{KIT}-6$ (7.6) catalyst compared to $\mathrm{WO}_{3} / \mathrm{SiO}_{2}$ (7.4) catalyst (28.4 $\pm 0.3 \%$ propene yield). Separate 2-butene conversion and propene selectivity profiles (from which the yield profile was derived) are shown in Fig. S18. 


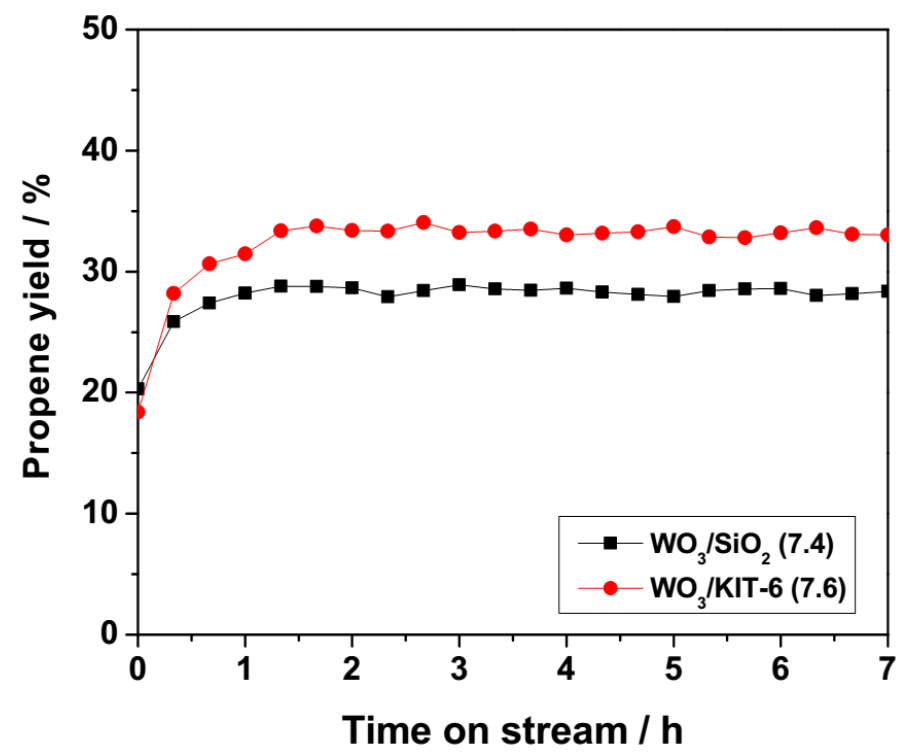

Fig. 3. Propene yield as a function of time on stream for two $\mathrm{WO}_{3}$-impregnated supports, $\mathrm{WO}_{3} / \mathrm{SiO}_{2}$ (7.4) and $\mathrm{WO}_{3} / \mathrm{KIT}-6$ (7.6) at $T=450^{\circ} \mathrm{C}, P=1 \mathrm{~atm}, \mathrm{WHSV}$ (ethylene and 2-butene) $=2.0 \mathrm{~h}^{-1}, n($ ethylene $) / n(2$-butene $)=3 / 1$.

On catalysts synthesized by the impregnation method $\left(\mathrm{WO}_{3} / \mathrm{SiO}_{2}\right.$ and $\left.\mathrm{WO}_{3} / \mathrm{KIT}-6\right)$, dispersed surface tungsten species and/or bulk $\mathrm{WO}_{3}$ species are formed on the surface (Figs. 2 and S3). It is known that bulk $\mathrm{WO}_{3}$ species are not active for the metathesis reaction of ethylene and 2butene to propene $[10,26,43]$. Experiments performed with commercially purchased bulk $\mathrm{WO}_{3}$ sample reveal no propene formation supporting this conclusion. The extent of surface silanol (Si$\mathrm{OH}$ ) groups dictates how many active tungsten precursors can be grafted on the surface. As shown in Scheme 1a, tungsten loading in excess of the available silanol groups will result in the formation of inactive bulk $\mathrm{WO}_{3}$ species on the support. In order to further increase the number of active tungsten precursors, ordered mesoporous silicas (OMS), in which the tungsten was incorporated into the framework to generate active precursors, were used as supports to synthesize the metathesis catalysts (Scheme 1b). 


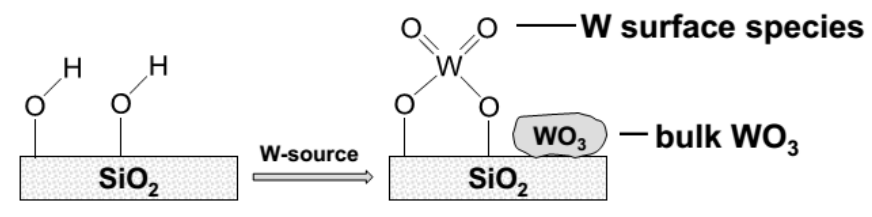

\section{(b) One pot synthesis of W incorporated OMS supports}
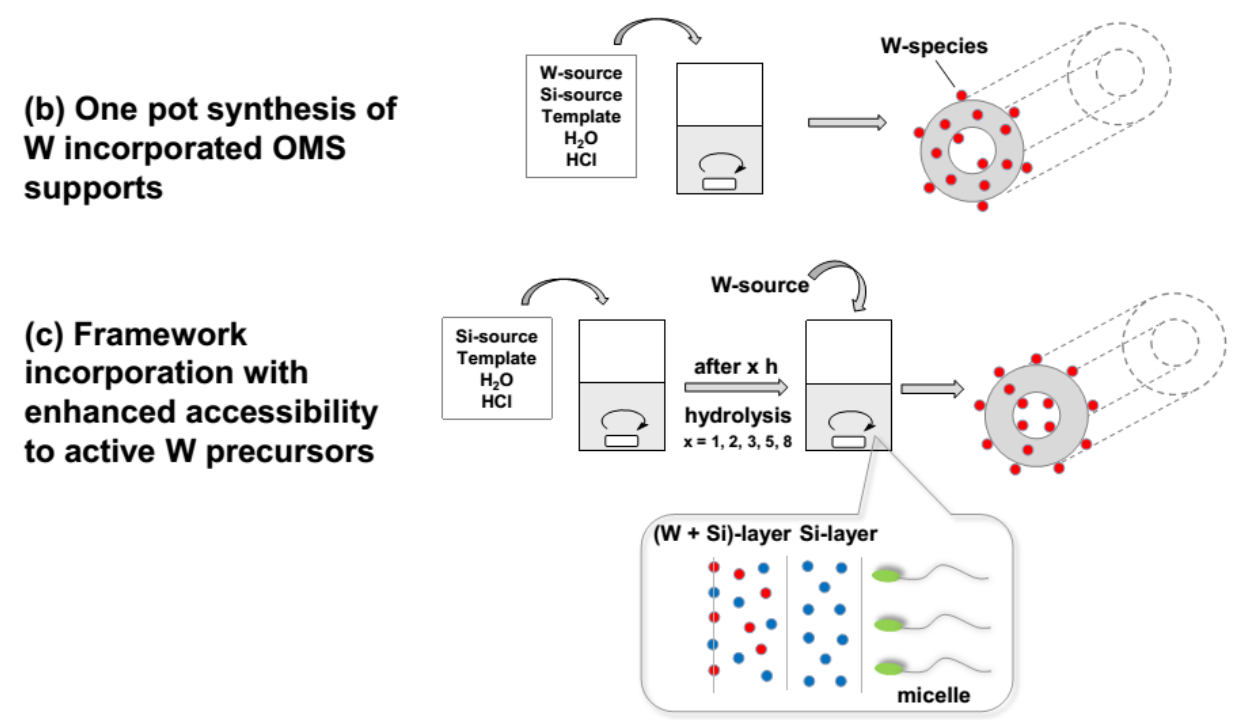

Scheme 1. Increasing the amount and accessibility of active W precursors by various synthesis methods. (a) Impregnation method; (b) One pot synthesis of W incorporated OMS supports; (c) Framework incorporation with enhanced accessibility to active $\mathrm{W}$ precursors.

\subsection{Metathesis activity of tungsten-incorporated W-KIT-6}

The propene yield profile with conventionally prepared W-KIT-6 catalysts with different W loadings is shown in Fig. 4. All the W-KIT-6 catalysts show steady yield after the break-in period (about $1.5 \mathrm{~h}$ ). The propene yield increases from $\sim 35 \%$ at $2.8 \mathrm{wt} \% \mathrm{~W}$ to $\sim 46 \%$ at $5.9 \mathrm{wt} \%$ $\mathrm{W}$, and then decreases to $\sim 37 \%$ at $13.7 \mathrm{wt} \% \mathrm{~W}$ (Figs. $4 \mathrm{a}$ and $4 \mathrm{~b}$ ). The corresponding 2-butene conversion and propene selectivity profiles for W-KIT-6 catalysts are shown in Fig. S19. As observed from the UV/Vis DRS patterns (Fig. 2), while the peak intensity corresponding to bulk $\mathrm{WO}_{3}$ is not evident at lower $\mathrm{W}$ loadings (up to $4.1 \mathrm{wt} \% \mathrm{~W}$ ), it becomes increasingly evident at higher $\mathrm{W}$ loadings. Correlating the trend of $\mathrm{WO}_{3}$ peak intensity with the propene yield, it follows that bulk $\mathrm{WO}_{3}$ species exhibit little or no metathesis activity. A control experiment (not shown here) with bulk $\mathrm{WO}_{3}$ displays no metathesis activity, supporting this conclusion. It also follows from the intensities variation of the bands at 225 and $262 \mathrm{~nm}$ at all W loadings (Fig. 2) that these framework tungsten species in tetrahedral and octahedral configurations are the active species. In addition, we observed that the propene yield also follows the variation of total acidity with $\mathrm{W}$ loading (Fig. 4b). The total acidity of the various W-KIT-6 samples are provided in Fig. S24 in the supporting information. 

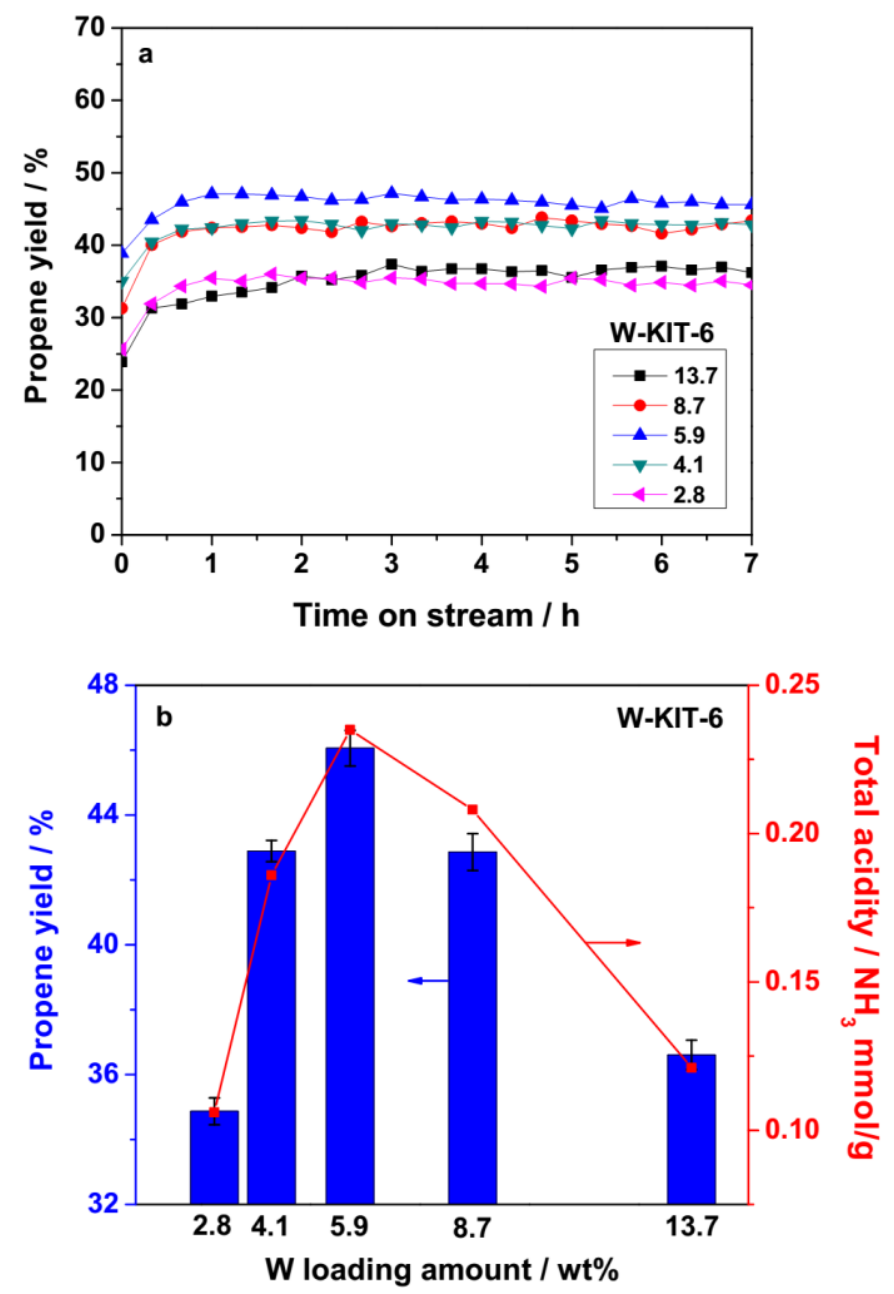

Fig. 4. (a) Propene yield as a function of time on stream of W-KIT-6 catalysts with different loadings $(2.8,4.1,5.9,8.7$, and $13.7 \mathrm{wt} \%)$ at $T=450^{\circ} \mathrm{C}, P=1 \mathrm{~atm}$, WHSV (ethylene and 2butene $)=2.0 \mathrm{~h}^{-1}, n$ (ethylene $) / n(2$-butene $)$ in feed $=3 / 1$. (b) Propene yield and catalyst total acidity as a function of tungsten loading amount on W-KIT-6 catalysts.

\subsection{Metathesis activities of W-SBA-16 and W-KIT-5 catalysts}

Figs. 5a and 5b show propene yield and total catalyst acidity as a function of $\mathrm{W}$ loading for $\mathrm{W}$ KIT-5 and W-SBA-16 catalysts, respectively. As observed with W-KIT-6 catalysts, the propene yield and total catalyst acidity display a maximum with an intermediate W loading (Fig. 5). Further, the maximum propene yields were similar ( 45\%) on all W-incorporated mesoporous materials. These results suggest that the active surface $\mathrm{W}$ precursors in the various $\mathrm{W}$ incorporated mesoporous silicates are similar. The 2-butene conversion, propene selectivity, UV/Vis spectra, and total catalyst acidity results for W-SBA-16 and W-KIT-5 materials are provided in the supporting information (Figs. S14-S15, S20-S21, S25-S26). 

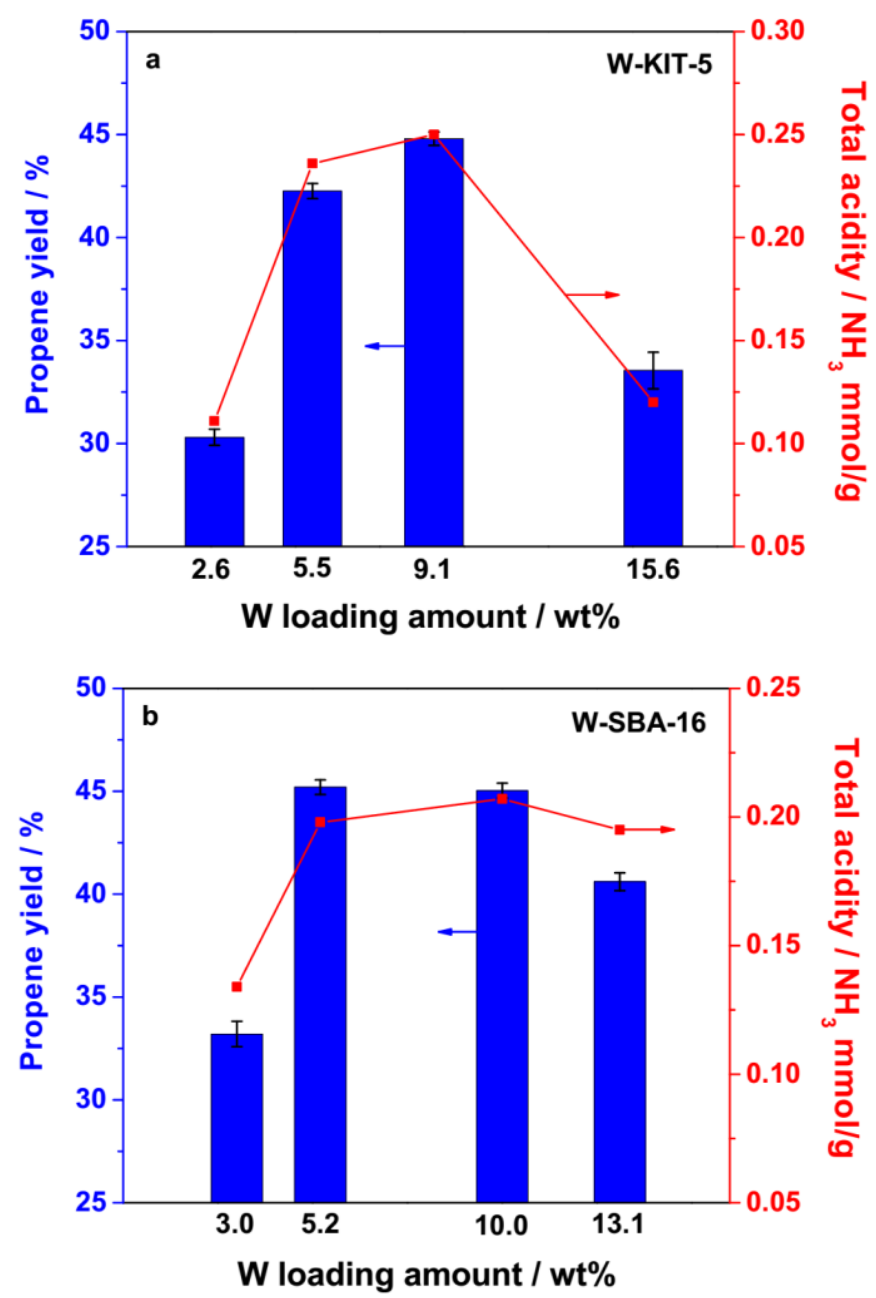

Fig. 5. Propene yield and total catalyst acidity as a function of tungsten loading on (a) W-KIT-5 catalysts and (b) W-SBA- 16 catalysts at $T=450^{\circ} \mathrm{C}, P=1 \mathrm{~atm}$, WHSV (ethylene and 2-butene) = $2.0 \mathrm{~h}^{-1}, n($ ethylene $) / n(2$-butene $)=3 / 1$.

\subsection{Metathesis activity of W-KIT-6 prepared by delayed addition of W source}

Considering the relatively thick walls of mesoporous silicates $(\sim 2-6 \mathrm{~nm})$, it is likely that some of the framework W species are buried in the walls and hence inaccessible. To minimize such inaccessible W species, we attempted a modified synthesis approach in which the Si and W sources were not added simultaneously. Rather, the Si source (TEOS) is allowed to hydrolyze partially to first form a Si-layer near the micelle. After a few hours, the $\mathrm{W}$ source (sodium tungstate) is added which then forms a $(\mathrm{W}+\mathrm{Si}$ ) layer on top of the Si layer (Scheme 1c).

Compared with the performance of the conventional W-KIT-6 catalysts (Fig. 4b), we find the propene yield obtained with the modified W-KIT-6 (2 h) catalysts (Fig. 6) are higher at tungsten loadings greater than $7.2 \mathrm{wt} \%$. The best catalytic performance $(59.2 \pm 0.5 \%$ propene yield $)$ is achieved at $9.2 \mathrm{wt} \%$ tungsten loading. The total acidity of the W-KIT-6 (2 h, 9.2) catalyst is 0.30 $\mathrm{mmol} / \mathrm{g}$, which is higher than the best performing conventional W-KIT-6 (5.9) catalyst with a total acidity of $0.23 \mathrm{mmol} / \mathrm{g}$ (Fig. 4). The corresponding 2-butene conversion, propene selectivity, 
UV/Vis spectra, and total catalyst acidity results are provided in the supporting information (Figs. S16, S22, S27). A comparison of XRD and UV/Vis data of the conventional W-KIT-6 (5.9) catalyst and the modified W-KIT-6 (2 h) catalyst with similar W loadings can be found in the supporting information (Figs. S7 and S17).

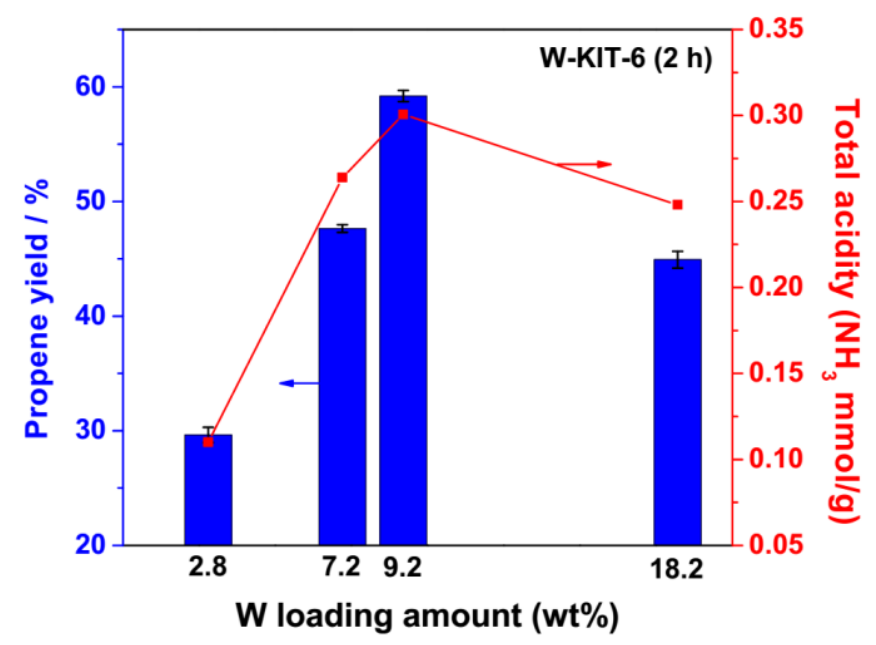

Fig. 6. Propene yield and catalyst total acidity as a function of tungsten loading on modified WKIT-6 ( $2 \mathrm{~h}$ ) catalysts at $T=450^{\circ} \mathrm{C}, P=1 \mathrm{~atm}$, WHSV (ethylene and 2-butene) $=2.0 \mathrm{~h}^{-1}$, $n($ ethylene $) / n(2$-butene $)=3 / 1$.

XPS results provide direct evidence that the catalyst surface is enriched with $\mathrm{W}$ species when the addition of the $\mathrm{W}$ source is delayed by $2 \mathrm{~h}$. As seen from Table 1, the surface W/Si atomic ratio is $42.6 \%$ greater in the case of the W-KIT-6 $(2 \mathrm{~h}, 9.2)$ catalyst compared to the W-KIT-6 (8.7) catalyst. In sharp contrast, the bulk W/Si atomic ratio, measured by ICP analysis, is only $6.8 \%$ greater in W-KIT-6 $(2 \mathrm{~h}, 9.2)$ catalyst compared to the W-KIT-6 (8.7) catalyst. The relevant XPS data are provided in the supporting information (Fig. S28).

\section{Table 1}

Comparison of X-ray photoelectron spectroscopy (XPS) and ICP analyses of used W-KIT-6 (8.7) and used W-KIT-6 (2 h, 9.2) catalysts.

\begin{tabular}{|c|c|c|c|c|c|c|}
\hline \multirow[b]{2}{*}{ Catalyst } & \multicolumn{4}{|c|}{ XPS results } & \multicolumn{2}{|c|}{ ICP results } \\
\hline & $\mathrm{W}(\%)^{\mathrm{a}}$ & $\mathrm{Si}(\%)^{\mathrm{b}}$ & $\begin{array}{l}\mathrm{W} / \mathrm{Si} \\
\text { atomic } \\
\text { ratio }\end{array}$ & $\begin{array}{c}\mathrm{W} / \mathrm{Si} \\
\text { increment } \\
(\%)^{\mathrm{c}}\end{array}$ & $\begin{array}{c}\text { W/Si } \\
\text { atomic } \\
\text { ratio }^{d}\end{array}$ & $\begin{array}{c}\mathrm{W} / \mathrm{Si} \\
\text { increment } \\
(\%)^{\mathrm{c}}\end{array}$ \\
\hline W-KIT-6 (8.7) & 2.74 & 97.3 & 0.0282 & 42.6 & 0.03204 & 6.8 \\
\hline W-KIT-6 (2 h, 9.2) & 3.86 & 96.1 & 0.0402 & & 0.03421 & \\
\hline
\end{tabular}

${ }^{\mathrm{a}}$ Atomic concentration, estimated from the peak area of $\mathrm{W}_{4 \mathrm{f}}$.

${ }^{\mathrm{b}}$ Atomic concentration, estimated from the peak area of $\mathrm{Si}_{2 \mathrm{p}}$.

${ }^{c}$ Normalized with W/Si ratio in catalyst prepared with no delay in W addition [W-KIT-6 (8.7)]

${ }^{\mathrm{d}}$ Based on analyses of $\mathrm{W}$ and $\mathrm{Si}$ in the synthesized catalyst samples 
We also compared the performances of modified W-KIT- 6 catalysts synthesized by delayed addition of the $\mathrm{W}$ source at 1, 2, 3, 5 and $8 \mathrm{~h}$ (Table 2 and Fig. S23). The $\mathrm{W}$ loading in these catalysts was similar (9.2-9.9 $\mathrm{wt} \%)$. The apparent TOF increased as the tungsten source addition was delayed from 1 to $2 \mathrm{~h}$, but decreased when delayed beyond $2 \mathrm{~h}$. This suggests increased availability of active $\mathrm{W}$ precursors when the addition of the $\mathrm{W}$ source is delayed by up to $2 \mathrm{~h}$. In contrast, without $\mathrm{W}$ addition for $3.5 \mathrm{~h}$, the hydrolysis of the Si source (TEOS) results in a cottonlike precipitate. Hence, when the tungsten source addition is delayed beyond $3 \mathrm{~h}$, the tungsten species are formed mainly on the catalyst surface similar to the $\mathrm{WO}_{3}$ impregnation method, with a reduced propene yield. The apparent TOFs of other W-catalysts are shown in the supporting information (Table S2).

\section{Table 2}

Apparent TOF of W-KIT-6 (x h) catalysts $(\mathrm{x}=1,2,3,5,8)$ with similar W loading (9.2-9.9 wt\%) at $T=450^{\circ} \mathrm{C}, P=1 \mathrm{~atm}$, WHSV (ethylene and 2-butene) $=2.0 \mathrm{~h}^{-1}, n$ (ethylene $) / n(2$-butene $)=3 / 1$.

\begin{tabular}{ccc}
\hline Catalysts & Time of W addition (h) & Apparent TOF $\left(\mathrm{mmol}_{\text {propene }}\right.$ mol $\left._{\mathrm{W}}{ }^{-1} \mathrm{~s}^{-1}\right)$ \\
\hline W-KIT-6 $(1 \mathrm{~h}, 9.3)$ & 1 & $3.97 \pm 0.01$ \\
W-KIT-6 $(2 \mathrm{~h}, 9.2)$ & 2 & $4.69 \pm 0.04$ \\
W-KIT-6 (3 h, 9.9) & 3 & $3.96 \pm 0.03$ \\
W-KIT-6 (5 h, 9.3) & 5 & $3.23 \pm 0.02$ \\
W-KIT-6 (8 h, 9.7) & 8 & $2.92 \pm 0.03$ \\
\hline
\end{tabular}

\subsection{Long-term stability of W-KIT-6 (2 h, 9.2) catalyst at $500^{\circ} \mathrm{C}$}

The stability of W-KIT-6 (2 h, 9.2) catalyst during a $120 \mathrm{~h}$ run at $500^{\circ} \mathrm{C}$ is shown in Fig. 7. Clearly, the propene yield increased significantly at $500^{\circ} \mathrm{C}$ compared to the results at $450^{\circ} \mathrm{C}$ (Fig. 6 and Fig. S22). During a $120 \mathrm{~h}$ continuous run, the 2-butene conversion declined from $84.2 \pm$ $0.1 \%$ to $79.4 \pm 0.1 \%$ ), and the propene yield decreased from $79.2 \pm 0.1$ to $72.6 \pm 0.1 \%$ indicating that the W-KIT-6 $(2 \mathrm{~h}, 9.2)$ catalyst activity is quite stable. These results show the W-KIT-6 ( $2 \mathrm{~h}$, 9.2) catalyst is quite coke resistant. Following regeneration of the used W-KIT-6 (2 h, 9.2) catalyst in air $\left(100 \mathrm{ml} / \mathrm{min}, 550^{\circ} \mathrm{C}, 5 \mathrm{~h}\right)$, its stability was tested during a further $72 \mathrm{~h}$ run. The 2butene conversion declined from $81.5 \pm 0.2 \%$ to $80.0 \pm 0.3 \%$, and the propene yield decreased from $76.2 \pm 0.2 \%$ to $73.5 \pm 0.3 \%$ indicating that the regenerated W-KIT-6 $(2 \mathrm{~h}, 9.2)$ catalyst is still quite stable and can be reused. 


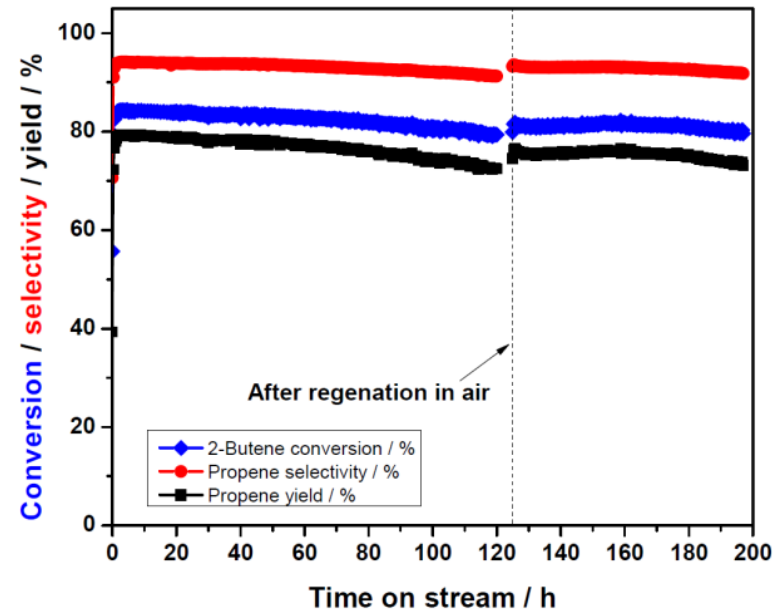

Fig. 7. Long-term stability of W-KIT-6 (2 h, 9.2) catalyst during a $120 \mathrm{~h}$ running and its performance following catalyst regeneration in air after $72 \mathrm{~h}$. Other conditions are $T=500^{\circ} \mathrm{C}, P$ $=1 \mathrm{~atm}, \mathrm{WHSV}$ (ethylene and 2-butene $)=2.0 \mathrm{~h}^{-1}, n($ ethylene $) / n(2$-butene $)=3 / 1$.

\subsection{Metathesis activity and selectivity}

All the W-catalysts were tested in the cross-metathesis of 2-butene and ethylene at 450 and/or $500^{\circ} \mathrm{C}$ (Figs. 3, 4a, 7, and Figs. S18-S23) and the comparative results are summarized in Table 3. The 2-butene conversion, propene selectivity, and 1-butene selectivity remain stable after an approximately $1.5 \mathrm{~h}$ initial break-in period. The targeted product, propene, is believed to form primarily through two pathways (Scheme 2): the cross-metathesis of 2-butene and ethylene (Reaction 1) and the cross-metathesis of 2-butene and 1-butene (Reaction 4). The main byproduct on all W-catalysts tested in this work is 1-butene, which is mainly generated through the isomerization of 2-butene (Reaction 2). Other byproducts include pentenes, hexanes, heptenes, and octenes with their total selectivity being less than $2 \%$ (Table 3). 2-Pentene is generated via the cross-metathesis of propene and 1-butene (Reaction 3) and the cross-metathesis of 1-butene and 2-butene (Reaction 4).

The cross-metathesis of 2-butene and ethylene to propene and the isomerization of 2-butene to 1butene are parallel reactions. Based on the relatively low selectivity of pentenes (Table 3), the contributions of Reactions 3 and 4 (Scheme 2) are relatively insignificant. Hence, the propene selectivity depends primarily on the competition between Reactions 1 and 2. As clearly borne out by the catalyst evaluation results, propene yield is favored by an increased amount of active W species on the catalyst surface. This conclusion is also supported by XPS results. 


\section{Table 3}

Conversion, selectivity and propene yield for various catalysts with $P=1 \mathrm{~atm}$, WHSV (ethylene and 2-butene $)=2.0 \mathrm{~h}^{-1}, n$ (ethylene $) / n(2$-butene $)=3 / 1, T=450^{\circ} \mathrm{C}$, except where noted.

\begin{tabular}{|c|c|c|c|c|c|}
\hline \multirow{2}{*}{ Catalysts } & \multirow{2}{*}{$\begin{array}{c}\text { 2-Butene } \\
\text { conversion }(\%)^{\mathrm{a}}\end{array}$} & \multicolumn{3}{|c|}{ Selectivity $(\%)^{\mathrm{a}}$} & \multirow{2}{*}{$\begin{array}{c}\text { Propene yield } \\
(\%)^{\mathrm{a}}\end{array}$} \\
\hline & & Propene & 1-Butene & Others $^{b}$ & \\
\hline $\mathrm{WO}_{3} / \mathrm{SiO}_{2}(7.4)$ & 47.0 & 60.5 & 38.6 & 1.0 & 28.4 \\
\hline $\mathrm{WO}_{3} / \mathrm{KIT}-6$ (7.6) & 50.2 & 66.2 & 32.4 & 1.4 & 33.2 \\
\hline W-KIT-6 (13.7) & 46.6 & 78.6 & 20.7 & 0.7 & 36.6 \\
\hline W-KIT-6 (8.7) & 54.9 & 78.1 & 20.9 & 1.0 & 42.9 \\
\hline W-KIT-6 (5.9) & 58.6 & 78.6 & 20.1 & 1.3 & 46.1 \\
\hline W-KIT-6 (4.1) & 54.7 & 78.4 & 20.6 & 1.0 & 42.9 \\
\hline W-KIT-6 (2.8) & 44.3 & 78.7 & 20.5 & 0.7 & 34.9 \\
\hline W-KIT-5 (15.6) & 45.4 & 73.9 & 25.2 & 0.8 & 33.5 \\
\hline W-KIT-5 (9.1) & 57.6 & 77.8 & 20.9 & 1.4 & 44.8 \\
\hline W-KIT-5 (5.5) & 56.1 & 75.3 & 23.3 & 1.4 & 42.3 \\
\hline W-KIT-5 (2.6) & 46.6 & 65.0 & 34.0 & 1.0 & 30.3 \\
\hline W-SBA-16 (13.1) & 53.0 & 76.4 & 22.6 & 0.7 & 40.5 \\
\hline W-SBA-16 (10.0) & 57.5 & 78.2 & 20.6 & 1.2 & 45.0 \\
\hline W-SBA-16 (5.2) & 58.3 & 77.6 & 21.0 & 1.4 & 45.3 \\
\hline W-SBA-16 (3.0) & 48.5 & 68.8 & 30.1 & 1.1 & 33.4 \\
\hline W-KIT-6 (2 h, 18.2) & 57.8 & 77.8 & 20.9 & 1.4 & 44.9 \\
\hline W-KIT-6 (2 h, 9.2) & 68.3 & 86.7 & 11.5 & 1.6 & 59.2 \\
\hline W-KIT-6 $(2 \mathrm{~h}, 9.2)^{\mathrm{C}}$ & 84.2 & 94.1 & 4.5 & 1.3 & 79.2 \\
\hline W-KIT-6 (2 h, 7.2) & 59.8 & 79.6 & 18.9 & 1.5 & 47.6 \\
\hline W-KIT-6 (2 h, 2.8) & 40.7 & 72.8 & 26.5 & 0.7 & 29.6 \\
\hline W-KIT-6 (1 h, 9.3) & 61.4 & 82.6 & 15.5 & 1.7 & 50.7 \\
\hline W-KIT-6 (3 h, 9.9) & 63.9 & 84.2 & 14.0 & 1.6 & 53.8 \\
\hline W-KIT-6 (5 h, 9.3) & 54.4 & 75.8 & 22.5 & 1.5 & 41.3 \\
\hline W-KIT-6 (8 h, 9.7) & 52.3 & 74.4 & 23.9 & 1.6 & 38.9 \\
\hline
\end{tabular}

${ }^{\mathrm{a} C}$ Conversion, selectivity and yield values represent averages obtained between 3 and $7 \mathrm{~h}$ on stream.

${ }^{\mathrm{b}}$ Pentenes, hexanes, heptenes, and octenes $\left(\mathrm{C}_{5}{ }^{ }\right.$and $\left.\mathrm{C}_{5}{ }^{+}\right)$.

${ }^{c}$ Reactions were performed at $500^{\circ} \mathrm{C}$

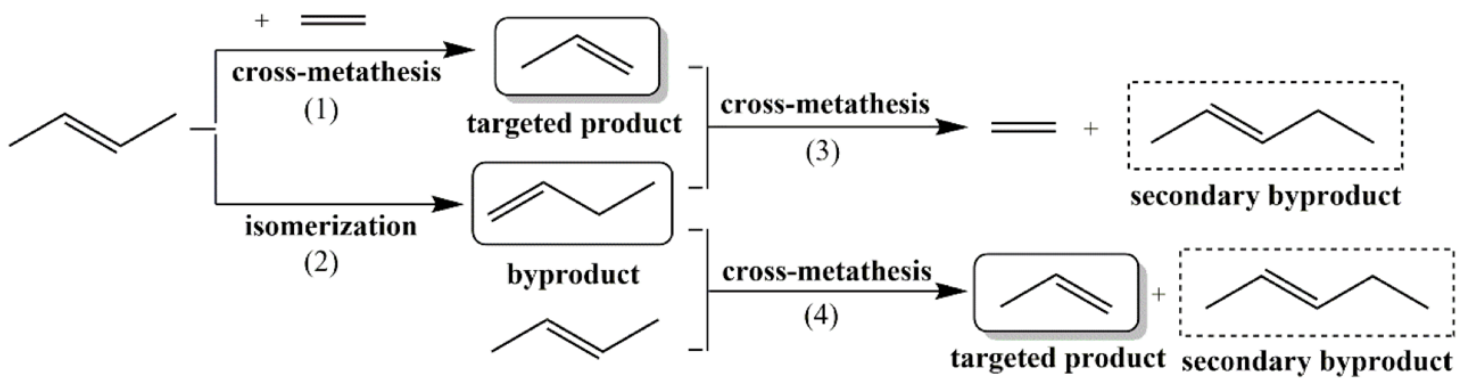

Scheme 2. Overall reaction network on W-incorporated mesoporous silicates with 2-butene and ethylene as reactants. 


\section{Conclusion}

W-incorporated mesoporous catalysts (W-KIT-6, W-KIT-5, and W-SBA-16) perform significantly better than $\mathrm{WO}_{3}$-impregnated catalysts $\left(\mathrm{WO}_{3} / \mathrm{SiO}_{2}\right.$ and $\left.\mathrm{WO}_{3} / \mathrm{KIT}-6\right)$ for ethylene and 2-butene metathesis to propene. The superior performance of the $\mathrm{W}$-incorporated ordered mesoporous silicates stems from the higher dispersion of active tungsten precursors compared to $\mathrm{WO}_{3}$-impregnated catalysts. All the investigated $\mathrm{W}$-incorporated mesoporous silicates exhibit steady activity and stability at $450^{\circ} \mathrm{C}$ during $7 \mathrm{~h}$ runs in a fixed-bed reactor. Further, on all these catalysts, propene yield is similar and maximized at an optimum $\mathrm{W}$ loading and catalyst acidity, suggesting that the structural differences among these catalysts do not play a major role in their performance.

It was demonstrated that optimally delayed addition of the $\mathrm{W}$ source (instead of simultaneous addition with the Si source) results in a better dispersion of active tungsten precursors on the surface of the catalyst rather than being buried in the walls. The better dispersion was manifested in improved metathesis activity as also supported by $\mathrm{NH}_{3}$-TPD measurements and XPS results. The best performing W-KIT- 6 catalyst $(9.2 \mathrm{wt} \% \mathrm{~W}$ and $2 \mathrm{~h}$ delayed addition of $\mathrm{W}$ source) exhibited about $79 \%$ propene yield at $500^{\circ} \mathrm{C}$ that was nearly stable during a $120 \mathrm{~h}$ extended run. Even the slight decrease in activity is easily regenerated by calcination in air.

\section{Acknowledgments}

The authors acknowledge financial support from several sources: U.S. Department of Agriculture and the National Institute of Food and Agriculture through Grant No. 2011-1000630362, Kansas Board of Regents K*STAR Program, and joint National Science Foundation and Environmental Protection Agency program Networks for Sustainable Material Synthesis and Design (NSF-EPA 1339661). We thank Prof. Franklin (Feng) Tao, Dr. Luan Nguyen and Dr. Shiran Zhang for helpful discussions about XPS, Dr. Prem S. Thapa for helping with XPS measurements, and Dr. Victor W. Day for helping with XRD measurements.

\section{References}

[1] Shale gas: Reshaping the US chemicals industry 2012 PwC, www.pwc.com/us/en/industrialproducts/publications/assets/pwc-shale-gas-chemicals-industry-potential.pdf.

[2] Foster, J. (2013). Can shale gale save the naphtha crackers? http://www.platts.com/im.platts.content/insightanalysis/industrysolutionpapers/shalegasreport13.p df.

[3] Y. Imamoglu, B. Zumreoglu-Karan, A.J. Amass, Olefin Metathesis and Polymerization Catalysts, Kluwer Academic Publishers, 1990.

[4] K.J. Ivin, J.C. Mol, Olefin Metathesis and Metathesis Polymerization, Academic Press, 1997.

[5] J.C. Mol, J. Mol. Catal. A: Chem. 213 (2004) 39-45.

[6] N. Popoff, E. Mazoyer, J. Pelletier, R.M. Gauvin, M. Taoufik, Chem. Soc. Rev. 42 (2013) 90359054. 
[7] K. Grela, Olefin Metathesis: Theory and Practice, John Wiley \& Sons, 2014.

[8] S. Lwin, I.E. Wachs, ACS Catal. 4 (2014) 2505-2520.

[9] N. Gholampour, M. Yusubov, F. Verpoort, Cat. Rev. Sci. Eng. 58 (2016) 113-156.

[10] A. Spamer, T.I. Dube, D.J. Moodley, C. van Schalkwyk, J.M. Botha, Appl. Catal. A: Gen. 255 (2003) 153-167.

[11] T.I. Bhuiyan, P. Arudra, M.N. Akhtar, A.M. Aitani, R.H. Abudawoud, M.A. Al-Yami, S.S. AlKhattaf, Appl. Catal. A: Gen. 467 (2013) 224-234.

[12] B.A. Zhang, N.S. Liu, Q.S. Lin, D. Jin, J. Mol. Catal. 65 (1991) 15-28.

[13] T. Ookoshi, M. Onaka, Chem. Commun. (1998) 2399-2400.

[14] T. Hahn, U. Bentrup, M. Armbruester, E.V. Kondratenko, D. Linke, ChemCatChem 6 (2014) 1664-1672.

[15] T. Hahn, E.V. Kondratenko, D. Linke, Chem. Commun. 50 (2014) 9060-9063.

[16] S.J. Huang, S.L. Liu, W.J. Xin, J. Bai, S.J. Xie, Q.X. Wang, L.Y. Xu, J. Mol. Catal. A: Chem. 226 (2005) 61-68.

[17] X.J. Li, W.P. Zhang, S.L. Liu, L.Y. Xu, X.W. Han, X.H. Bao, J. Catal. 250 (2007) 55-66.

[18] Q. Zhao, S.-L. Chen, J. Gao, C. Xu, Transition Met. Chem. 34 (2009) 621-627.

[19] D.P. Debecker, B. Schimmoeller, M. Stoyanova, C. Poleunis, P. Bertrand, U. Rodemerck, E.M. Gaigneaux, J. Catal. 277 (2011) 154-163.

[20] D.P. Debecker, M. Stoyanova, F. Colbeau-Justin, U. Rodemerck, C. Boissiere, E.M. Gaigneaux, C. Sanchez, Angew. Chem. Int. Ed. 51 (2012) 2129-2131.

[21] M. Taoufik, E. Le Roux, J. Thivolle-Cazat, J.M. Basset, Angew. Chem. Int. Ed. 46 (2007) 72027205.

[22] E. Mazoyer, K.C. Szeto, N. Merle, S. Norsic, O. Boyron, J.M. Basset, M. Taoufik, C.P. Nicholas, J. Catal. 301 (2013) 1-7.

[23] A.W. Moses, C. Raab, R.C. Nelson, H.D. Leifeste, N.A. Ramsahye, S. Chattopadhyay, J. Eckert, B.F. Chmelka, S.L. Scott, J. Am. Chem. Soc. 129 (2007) 8912-8920.

[24] H. Liu, K. Tao, P.P. Zhang, W. Xu, S.H. Zhou, New J. Chem. 39 (2015) 7971-7978.

[25] K. Tao, Q.X. Ma, N. Tsubaki, S.H. Zhou, L. Han, J. Mol. Catal. A: Chem. 416 (2016) 39-46.

[26] D.R. Hua, S.L. Chen, G.M. Yuan, Y.L. Wang, Q.F. Zhao, X.L. Wang, B. Fu, Microporous Mesoporous Mater. 143 (2011) 320-325.

[27] B. Hu, H. Liu, K. Tao, C.R. Xiong, S.H. Zhou, J. Phys. Chem. C 117 (2013) 26385-26395.

[28] W. Xu, C. Lin, H. Liu, H.B. Yu, K. Tao, S.H. Zhou, RSC Adv. 5 (2015) 23981-23989.

[29] K. Bouchmella, P.H. Mutin, M. Stoyanova, C. Poleunis, P. Eloy, U. Rodemerck, E.M. Gaigneaux, D.P. Debecker, J. Catal. 301 (2013) 233-241.

[30] R.D. Andrei, M.I. Popa, C. Cammarano, V. Hulea, New J. Chem. 40 (2016) 4146-4152.

[31] Z. Cheng, C.S. Lo, ACS Catal. 2 (2012) 341-349.

[32] Z. Cheng, C.S. Lo, ACS Catal. 5 (2015) 59-72.

[33] A. Taguchi, F. Schuth, Microporous Mesoporous Mater. 77 (2005) 1-45.

[34] D. Zhao, Y. Wan, W. Zhou, Ordered mesoporous materials, John Wiley \& Sons, 2012.

[35] B. Hu, C. Xiong, K. Tao, S. Zhou, J. Porous Mater. 22 (2015) 613-620.

[36] C. Lin, K. Tao, H.B. Yu, D.Y. Hua, S.H. Zhou, Catal. Sci. Technol. 4 (2014) 4010-4019.

[37] D.P. Debecker, K. Bouchmella, C. Poleunis, P. Eloy, P. Bertrand, E.M. Gaigneaux, P.H. Mutin, Chem. Mater. 21 (2009) 2817-2824.

[38] D.P. Debecker, K. Bouchmella, M. Stoyanova, U. Rodemerck, E.M. Gaigneaux, P.H. Mutin, Catal. Sci. Technol. 2 (2012) 1157-1164.

[39] K. Bouchmella, M. Stoyanova, U. Rodemerck, D.P. Debecker, P.H. Mutin, Catal. Commun. 58 (2015) 183-186.

[40] S. Maksasithorn, P. Praserthdam, K. Suriye, M. Devillers, D.P. Debecker, Appl. Catal. A: Gen. 488 (2014) 200-207.

[41] A. Ramanathan, B. Subramaniam, D. Badloe, U. Hanefeld, R. Maheswari, J. Porous Mater. 19 (2012) 961-968. 
[42] A. Ramanathan, R. Maheswari, B.P. Grady, D.S. Moore, D.H. Barich, B. Subramaniam, Microporous Mesoporous Mater. 175 (2013) 43-49.

[43] R. Thomas, J.A. Moulijn, V.H.J. Debeer, J. Medema, J. Mol. Catal. 8 (1980) 161-174.

[44] X.-L. Yang, W.-L. Dai, R. Gao, K. Fan, J. Catal. 249 (2007) 278-288.

[45] T.W. Kim, F. Kleitz, B. Paul, R. Ryoo, J. Am. Chem. Soc. 127 (2005) 7601-7610.

[46] C. van Schalkwyk, A. Spamer, D.J. Moodley, T. Dube, J. Reynhardt, J.M. Botha, Appl. Catal. A: Gen. 255 (2003) 121-131.

[47] R. Maheswari, M.P. Pachamuthu, A. Ramanathan, B. Subramaniam, Ind. Eng. Chem. Res. 53 (2014) 18833-18839.

[48] J.J. Shan, W.X. Huang, L. Nguyen, Y. Yu, S.R. Zhang, Y.Y. Li, A.I. Frenkel, F. Tao, Langmuir 30 (2014) 8558-8569.

[49] E. Briot, J.Y. Piquemal, M. Vennat, J.M. Bregeault, G.A. Chottard, J.M. Manoli, J. Mater. Chem. 10 (2000) 953-958.

[50] S.K. Gangwal, J. Fathikalajahi, G.B. Wills, Ind. Eng. Chem. Prod. Rd. 16 (1977) 237-241.

[51] A. Andreini, J.C. Mol, J. Colloid Interface Sci. 84 (1981) 57-65.

[52] R.C. Luckner, G.B. Wills, J. Catal. 28 (1973) 83-91. 